\title{
Submandibular thyroid
}

\author{
B. Karki, ${ }^{1}$ P. Sharma, ${ }^{2}$ P. G. Ghimire ${ }^{3}$
}

${ }^{1}$ Department of General Surgery Nepalgunj Medical College Teaching Hospital, ${ }^{2}$ Department of Radiology and Imaging Nepalgunj Medical College Teaching Hospital, ${ }^{3}$ Department of Pathology, Nepalgunj Medical College Teaching hospital, Banke, Nepal

Correspondence to: Dr. B. Karki, Department of General Surgery, Nepalgunj Medical College

Email: bishal_karki32@yahoo.com

\begin{abstract}
Submandibular thyroid is one of the rare locations of ectopic thyroid tissue. Only few cases have been reported in the literature. We report a case of 16 year old female patient presenting with ectopic submandibular thyroid tissue. Diagnosis was based on ultrasound and cytology.
\end{abstract}

Keywords: Nepal, submandibular ectopic thyroid

\section{Introduction}

Arrest in the descent of the thyroid gland at any point along the thyroglossal duct results in ectopic thyroid. It can present as a mass in the neck. Sometimes it may represent the only thyroid tissue present in the body. Ectopic thyroid tissue presenting in submandibular space is rare. ${ }^{1,2}$ Eighteen similar cases of ectopic thyroid tissue have been reported in the submandibular space. ${ }^{1}$ Proper clinical, radiological and histological examination is required for the diagnosis and management of such condition. To the best of our knowledge, this is the first case to be reported from Nepal.

\section{Case report}

A 16-year old female presented with chief complaints of swelling over the upper part of neck for 10 years. It was gradually progressive in size. There was no history of pain, sudden increase or decrease in the size of the swelling. There was no dyspnoea, hoarseness of voice or dysphagia.

On examination, she was calm and had pulse rate was 72 beats per minute. Local examination revealed a single swelling of $5 \times 4 \mathrm{~cm}$ size located in the right submandibular position (Fig. 1). It had smooth surface, firm, non tender with doubtful movement on deglutition. There was no associated lymphadenopathy. Other systems revealed no abnormality.

Thyroid profile was normal. Ultrasound of the neck revealed

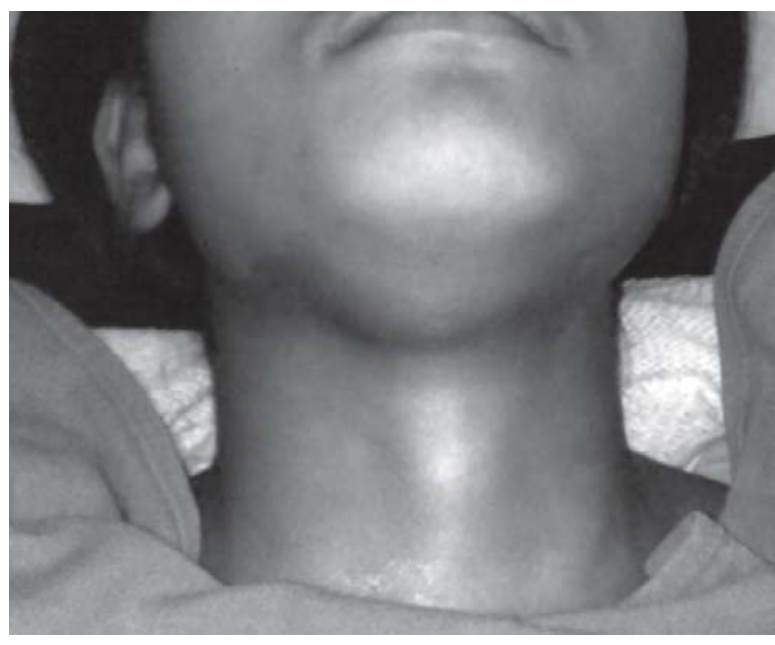

Fig. 1: Swelling in the right submandibular space

empty thyroid fossa (Fig. 2). There was a heterogeneous lesion measuring $4.9 \times 4.5 \mathrm{~cm}$ in the right submandibular region with few hyperechoeic foci with comet-tail artefact (Fig. 3). There was no cervical lymphadenopathy. Ultrasound guided fine needle aspiration cytology (FNAC) showed the presence of thyroid follicular cells (Fig. 4). Thyroid scan was not done because of its unavailability. Hence the lesion was diagnosed as ectopic thyroid. Apart from the swelling she had no other complaints, so no interventions were carried out and she is being followed up regularly. 


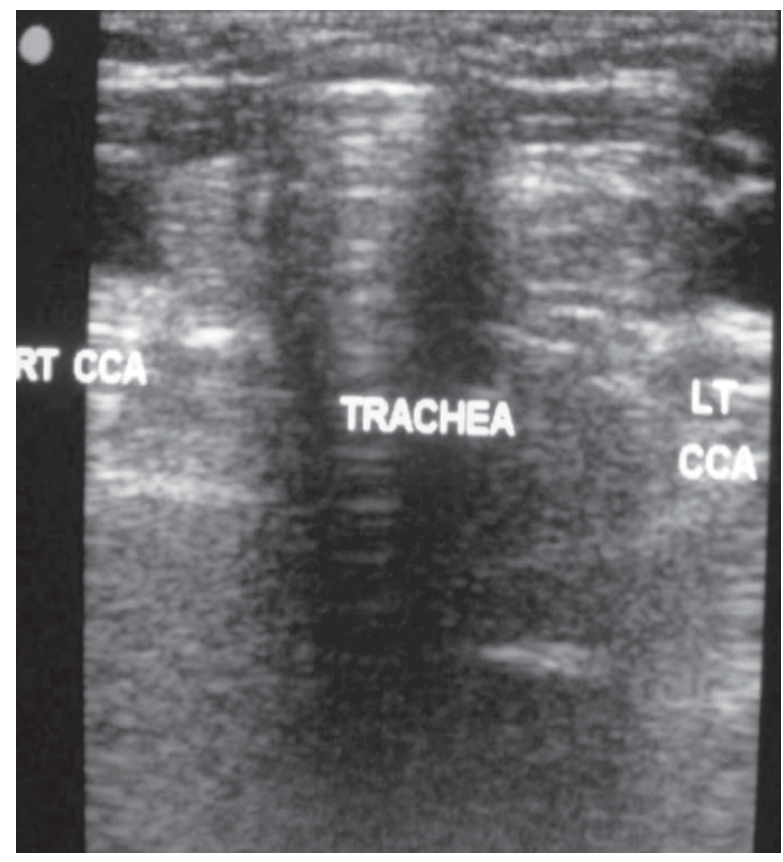

Fig. 2: Ultrasound neck showing empty thyroid fossa

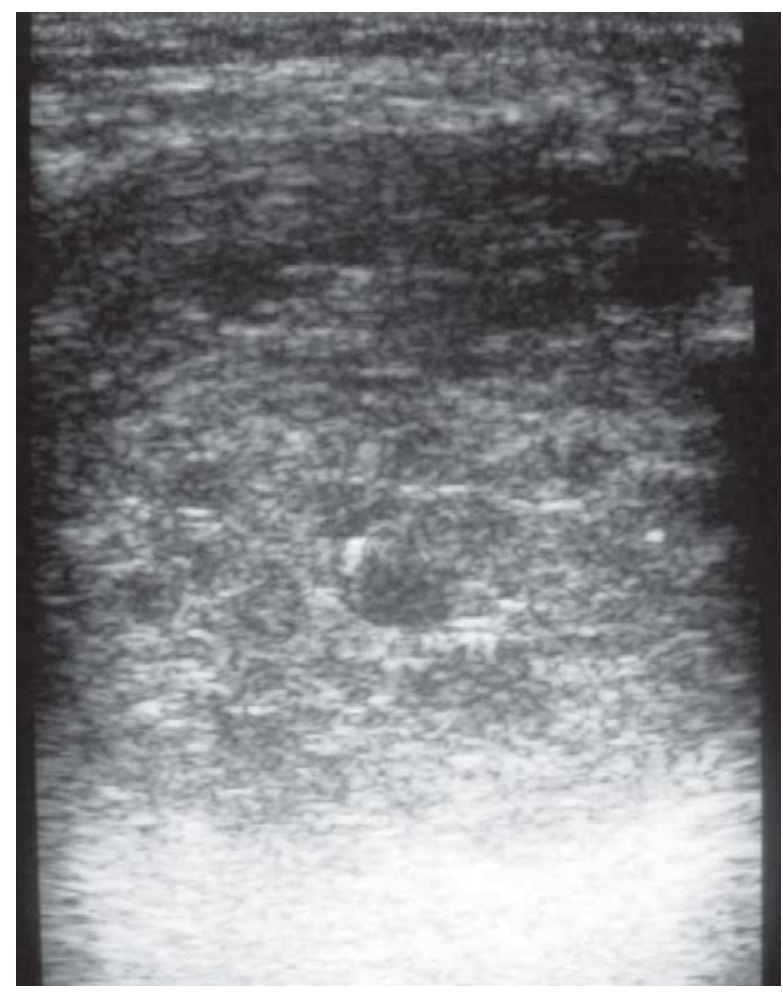

Fig. 3: Ultrasound neck showing heterogenous lesion with few hyperechoiec foci in the right submandibular region

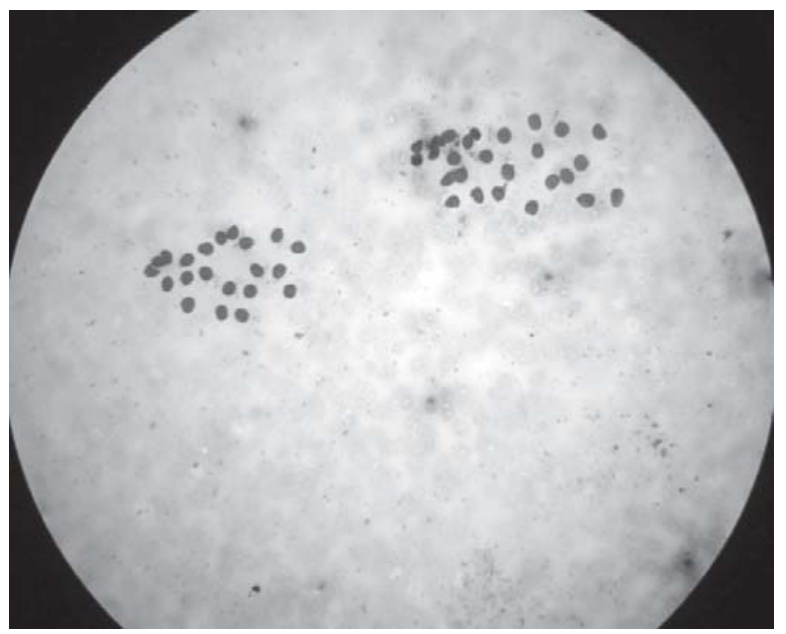

Fig. 4: Smear showing thyroid follicular cells in Giemsa stain.

\section{Discussion}

The thyroid gland is the first of the body's endocrine glands to develop, on approximately the $24^{\text {th }}$ day of gestation. ${ }^{3}$ It originates as a proliferation of endodermal epithelial cells on the median surface of the developing pharyngeal floor. ${ }^{3}$ The site of this initial development lies between two key structures, the tuberculum impar and the copula, and is known as the foramen cecum. The initial descent of the thyroid gland occurs anterior to the pharyngeal gut. At this point, the thyroid is still connected to the tongue via the thyroglossal duct. The tubular duct later solidifies and subsequently obliterates entirely (during gestational weeks 7-10). As the thyroid gland descends, it forms its mature shape, with a median isthmus connecting two lateral lobes. The thyroid completes its descent in the seventh gestational week, coming to rest in its final location immediately anterior to the trachea. ${ }^{3}$

An ectopic thyroid gland may occur anywhere along the path of initial descent of the thyroid, although it is most common at the base of the tongue, just posterior to the foramen cecum. This failure to descend contrasts with the incomplete descent of the thyroid, in which case the resulting final resting point of the gland may be high in the neck or just below the hyoid bone. ${ }^{4}$

This ectopic gland may represent the only functional thyroid tissue in $70 \%$ of cases. ${ }^{4}$

Ultrasound is an excellent, non-invasive and portable imaging method for studying thyroid gland. CT and MRI can also be used for exact localization of ectopic thyroid tissue. Radionuclide scan can also be used for the localization of ectopic thyroid tissue. It also provides 
information about the size and shape of the gland and distribution of the functional activity. ${ }^{5}$ Due to the unavailability of thyroid scan; it was not done in our case.

The management of ectopic thyroid tissue depends on some factors such as size of the mass, local symptoms, state of the thyroid gland and related complications (e.g. ulceration, haemorrhage, malignancy). ${ }^{6}$ Surgical excision is rarely needed, but if required, should be preceded by an evaluation of normal thyroid tissue in the neck to avoid inadvertently rendering the patient hypothyroid. ${ }^{5}$ The treatment of choice in patients with dysphagia, dyspnoea and malignancy is surgical removal of the ectopic mass. ${ }^{7}$ If ectopic thyroid tissue is encountered at surgery, its blood supply should be preserved; the ectopic gland divided vertically; and each half translocated laterally, deep to the strap muscles, where it is no longer manifested as a mass. In our case, the patient was asymptomatic and she was not bothered about the cosmesis. Hence no surgical intervention was carried out and she is being regularly followed up.

\section{Conclusions}

In the differential diagnosis of a submandibular swelling, ectopic thyroid gland should be considered. Ultrasound can be used as a cheap modality to see the location of thyroid tissue in such conditions.

\section{References}

1. Zieren J, Paul M, Scharfenberg M, Menenakos C. Submandibular ectopic thyroid gland. J Craniofac Surg. 2006;17:1194-8.

2. Kanaya H, Tanigaito Y, Shyono N, Hirabayashi H, Baba $\mathrm{K}$. A rare case of ectopic, normally functioning thyroid tissue presenting as a left submandibuar mass. Nippon jibiinkoka Gakkai Kaiho. 2005;108:850-3.

3. Baughman RA. Lingual thyroid and lingual thyroglossal tract remnants. A clinical and histopathologic study with review of the literature. Oral Surg Oral Med Oral Pathol. 1972; 34:781-99.

4. Neville BW, Damm DD, Allen CM, Bouquot JE. Oral and maxillofacial pathology. 2nd ed. Philadelphia: Saunders Elsevier; p. 1-25.

5. Lal G, Clark OH. Thyroid, parathyoid, and adrenal. In: Brunicardi FC, Anderson DK, Billiar, Dunn DL, Hunter JG, Pollock RE, editors. Schwartz's principles of Surgery. 8th ed. New Delhi: McGraw-Hill Medical Publishing Division; 2005. p. 1396-1406.

6. Williams JD, Sclafani AP, Slupchinskij O, Douge C.
Evaluation and management of the lingual thyroid gland. Ann Otol Rhinol Laryngol 1996;105:312-6.

7. Maurice N, Makeieff M, Delol J, Bec P, Crampette L, Guerrier B. Ectopic lingual thyroid. Ann Otolaryngol Czhir Cervicofac 1995;112:399-405. 